\title{
MENGUKUR DAMPAK PELATIHAN TERHADAP IMPLEMENTASI BUDAYA KERJA PRODUKTIF DALAM RANGKA PENINGKATAN PRODUKTIVITAS MENGGUNAKAN SMARTPLS
}

\section{Measuring the Impact of Training on the Implementation of a Productive Work Culture in the Context of Increasing Productivity Using SmartPLS}

\author{
Yeni Nuraeni $^{1 *}$, Faizal Amir Nasution ${ }^{2}$, Zusfarlian Maulana $^{3}$ \\ 1,2,3 Pusat Pengembangan Kebijakan Kementerian Ketenagakerjaan \\ Jl Gatot Subroto Kav 51, Jakarta Selatan, 12950, Indonesia
}

Corresponding authore-mail:1*yeninur@hotmail.com

\begin{abstract}
Abstrak
Daya saing tenaga kerja Indonesia masih tertinggal dibandingkan sejumlah negara di dunia. Untuk itu pemerintah Indonesia perlu meningkatkan produktivitas tenaga kerja yang merupakan variabel penyusun daya saing. Salah satu upayanya dengan menyelenggarakan pelatihan berkaitan dengan produktivitas kerja. Penelitian ini bertujuan untuk melakukan evaluasi dan analisis dampak program pelatihan produktivitas yang diselenggarakan oleh pemerintah terhadap implementasi budaya kerja produktif di Indonesia. Penelitian ini menggunakan analisis data kuantitatif berupa analisis jalur dengan menggunakan software SmartPLS. Hasil penelitian menunjukkan bahwa budaya kerja produktif dapat mendorong produktivitas kerja, pelatihan kerja dapat mendorong budaya Kaizen, dan budaya kerja produktif secara langsung, tetapi pelatihan kerja tidak mendorong produktivitas kerja secara langsung. Budaya Kaizen memiliki hubungan positif dan signifikan terhadap produktivitas kerja secara tidak langsung, tetapi melalui budaya $5 \mathrm{~S}$ terlebih dahulu. Program pelatihan peningkatan produktivitas dan bimbingan konsultasi yang dilaksanakan oleh pemerintah perlu memperhatikan budaya kerja yang dominan diterapkan oleh perusahaan untuk mencapai produktivitas kerja yang tinggi.
\end{abstract}

Kata Kunci : Pelatihan produktivitas, budaya kerja produktif, budaya kerja kaizen, budaya kerja 5S, peningkatan produktivitas

\begin{abstract}
The competitiveness of Indonesian workers is still lagging behind several countries in the world. For this reason, the Indonesian government needs to increase labor productivity which is a component of competitiveness. One of the efforts is to organize training related to work productivity. This study aims to evaluate and analyze the impact of productivity training programs organized by the government on the implementation of productive work culture in Indonesia. This study uses quantitative data analysis in the form of path analysis using SmartPLS software. The results show that productive work culture can encourage work productivity, job training can encourage Kaizen culture, and a productive work culture directly, but job training does not directly encourage work productivity. Kaizen culture has a positive and significant relationship to work productivity indirectly, but through the $5 S$ culture first. The productivity improvement training program and consulting guidance by the government need to pay attention to the dominant work culture applied by companies to achieve high work productivity.
\end{abstract}

Keywords: Productivity training, productive work culture, kaizen work culture, $5 S$ work culture, productivity improvement

Article info:

Submitted: $05^{\text {th }}$ July 2021 Accepted: 01 $1^{\text {st }}$ November 2021

How to cite this article:

Y. Nuraeni, F. A. Nasution, and Z. Maulana, "MENGUKUR DAMPAK PELATIHAN TERHADAP IMPLEMENTASI BUDAYA KERJA PRODUKTIF DALAM RANGKA PENINGKATAN PRODUKTIVITAS MENGGUNAKAN SMARTPLS”, BAREKENG: J. Il. Mat. \& Ter., vol. 15, no. 04, pp. 675-686, Dec. 2021.

This work is licensed under a Creative Commons Attribution-ShareAlike 4.0 International License.

Copyright (c) 2021 Yeni Nuraeni, Faizal Amir Nasution, Zusfarlian Maulana 


\section{PENDAHULUAN}

Produktivitas dipandang sebagai indikator penting dalam aktivitas ekonomi. Penggunaan produktivitas oleh dunia internasional sebagai alat ukur kinerja suatu negara menjadikan nilai produktivitas dapat dibandingkan antar negara. Dengan demikian akan dapat dilihat posisi kinerja suatu negara dibandingkan negara lain sehingga kebijakan menjadi terarah dalam mengupayakan perbaikan-perbaikan peningkatan produktivitas agar mempu bersaing dengan negera lain dan semakin mampu mensejahterakan bangsa. Standar produktivitas mengacu pada efisiensi tenaga kerja dalam proses produksi, atau produktivitas tenaga kerja [1]. Dengan kata lain, inti dari produktivitas adalah tenaga kerja.

Tenaga kerja memegang peranan yang sangat penting dalam daya saing suatu negara. Tenaga kerja yang mempunyai produktivitas tinggi akan mampu meningkatkan daya saing suatu negera ke level yang lebih tinggi. Dalam implementasinya produktivitas dapat digunakan untuk mengukur daya saing tenaga kerja [2], [3]. Tenaga kerja menjadi faktor utama dalam membangun daya saing suatu negara, terdapat hubungan yang erat antara daya saing tenaga kerja dan daya saing ekonomi [4]. Hal ini menunjukkan bahwa untuk meningkatkan daya saing suatu negara, penting untuk meningkatkan daya saing tenaga kerjanya. Daya saing tenaga kerja akan berdampak pada upah, nilai tukar, dan standar hidup suatu negara. Standar hidup sendiri merupakan indikator utama daya saing suatu negara, sehingga dapat disimpulkan bahwa daya saing tenaga kerja menjadi penentu daya saing suatu negara [5].

Berdasarkan penelitian Institute for Management Development (IMD), daya saing tenaga kerja Indoneisa masih tertinggal dibandingkan sejumlah negara ASEAN seperti Thailand, Malaysia, dan Singapura. Sementara secara global, Indonesia berada di peringkat 47 dari 63 negara. Demi mengatasi daya saing tenaga kerja Indonesia yang masih tertinggal, pemerintah mengupayakan berbagai program seperti pelatihan vokasi, pemagangan berbasis kompetensi di perusahaan, dan sertifikasi kompetensi. Program tersebut dicanangkan dalam rangka pemenuhan tenaga kerja sesuai kebutuhan industri serta meningkatkan serapan tenaga kerja.

Pesatnya pertumbuhan ekonomi di Indonesia menyebabkan terjadinya persaingan pasar yang semakin ketat, hal ini menuntut setiap perusahaan untuk memiliki keunggulan bersaing dalam kualitas produk, harga bahkan sumbar daya manusia yang terlatih dan profesional [7]. Dapat dipastikan antara perusahaan dan karyawannya harus bekerja sama untuk memenangkan persaingan yang hanya dapat terwujud dengan peningkatan produktivitas kerja [8]. Untuk dapat meningkatkan produktivitas karyawan harus didorong untuk menjadi pribadi yang dinamis, kreatif, inovatif serta terbuka akan ide-ide baru dan perubahanperubahan, sehingga dapat tercipta korelasi peningkatan produktivitas individual dengan peningkatan produktivitas organisasi [9]. Nilai-nilai yang telah menjadi kebiasaan dinamakan budaya. Apabila budaya dikaitkan dengan kadar kualitas kerja, maka budaya disebut budaya kerja, baik di dalam maupun diluar organisasi. Penerapan budaya kerja yang digunakan di suatu organisasi akan meningkatkan kualitas kerja karyawan. Budaya perusahaan yang unggul perlu dipertahankan dan diperkuat serta diperkenalkan kepada karyawan dengan cara disosialisasikan agar persepsi karyawan seiring dengan niai-nilai perusahaan [10].

Kaizen merupakan istilah bahasa Jepang terhadap konsep continous incremental improvement. Kaizen berarti penyempurnaan yang berkesinambungan serta melibatkan semua orang [11]. Konsep budaya Kaizen merupakan perkembangan secara kontinu dan bertahap dalam rangka meningkatkan value, intensification dan improvement [12]. "Kaizen merupakan metode pengendalian kualitas yang memiliki prinsip melakukan perbaikan kecil secara bertahap untuk mencapai hasil yang diinginkan melalui siklus PDCA, yang terdiri dari tahapan plan-do-check-action" [13]. Karakteristik dari budaya Kaizen dapat disimpulkan adalah Kontinu, merupakan proses untuk menghargai perbaikan dari alam, perbaikan tidak hanya berlandaskan pada organisasi atau sebagai serta partisipatif [14]. Praktik Kaizen telah dilaksanakan diberbagai negara berkembang diseluruh dunia termasuk Indonesia, meskipun berbagai tantangan dapat dijumpai dalam upaya pengimplementasiannya [15], [16]. Ada beberapa faktor yang menentukan keberhasilan penerapan budaya Kaizen yaitu komitmen karyawan, keterlibatan dan partisipasi kerja, fokus serta kapasitas untuk mencoba dan mengalami tindakan perbaikan [15]. Kaizen menekankan upaya manusia, moral, komunikasi, pelatihan, kerjasama, pemberdayaan, dan disiplin diri, yang merupakan pendekatan akal sehat (commonsense), berbiaya rendah, sedangkan inovasi merupakan perbaikan yang drastis (drastic improvement)"[17] .

Dampak positif dari implementasi budaya Kaizen tidak hanya akan dirasakan oleh seluruh karyawan melainkan akan berdampak pada keseluruhan proses yang terjadi di dalam perusahaan [18]. Mempertahankan budaya Kaizen dapat meningkatkan proses kerja dan mengimplementasikan perampingan secara menyeluruh ke dalam supply chain [19]. Perbaikan berkelanjutan adalah usaha untuk memperoleh kualitas yang harus 
dilakukan secara terus-menerus dan karyawan perlu didorong untuk mengadopsi program peningkatan produktivitas yang akan berdampak pada peningkatan kinerja keuangan perusahaan [20]. Kaizen memiliki pola tersendiri untuk memperbaiki pemborosan yang masih terjadi agar tercipta kinerja yang efisien, baik dari segi biaya, peralatan, tenaga kerja, manajemen, dan waktu [21].

Untuk dapat membudayakan konsep Kaizen, perusahaan harus merangsang inovasi dari karyawan dengan mewajibkan kepada karyawannya untuk menulis ide-ide yang ditujukan untuk mempermudah pekerjaannya [22]. Penerapan "Kaizen" bisa dilakukan di awal proses produksi, pada saat proses produksi, hingga proses akhir barang tersebut disimpan digudang dan siap dikirim ke customer. Batasan-batasan sosial dan budaya serta kebutuhan untuk berkreatifitas merupakan input dari budaya Kaizen, adapun alat dan metode untuk melakukan perbaikan aktivitas di tempat kerja merupakan output dari Kaizen [23]. Dari sisi output barang yang dihasilkan memiliki nilai jual yang tinggi dengan kualitas yang baik. Sedangkan dari sisi input "Kaizen" akan menurunkan biaya produksi dengan cara menurunkan jumlah barang yang rusak [24]. Dampak positif dari implementasi budaya Kaizen tidak hanya akan dirasakan oleh seluruh karyawan melainkan akan berdampak pada keseluruhan proses yang terjadi di dalam perusahaan [18]. Budaya Kaizen yang terkenal sampai saat ini diantaranya menerapkan budaya konsep $5 \mathrm{~S}$, telah banyak diterapkan oleh beberapa negara termasuk Indonesia [25].

Manfaat dari penerapan budaya 5S dengan pengaturan tempat kerja yang lebih efisien, produktivitas kerja akan meningkat [26]. Perusahaan yang berhasil mengimplementasikan sikap kerja 5S, diharapkan akan dapat menciptakan kondisi lingkungan dan tempat kerja yang baik, aman, sehat, nyaman dan kondusif, sehingga setiap anggota perusahaan dapat mencapai kesuksesan dalam melaksanakan tugas sesuai dengan bidangnya masing-masing [27]. "Penerapan budaya kerja 5S dapat meningkatkan produktivitas kerja yang pada dasarnya merupakan proses perubahan sikap dengan menerapkan penataan dan kebersihan kerja atau secara umum adalah keselamatan dan kesehatan kerja" [28]. Adapun sasaran terahirnya dari penerapan konsep 5S adalah peningkatkan efektivitas dan peningkatkan produktivitas [29]. Budaya 5s merupakan dasar dari pengendalian mutu secara terpadu yang memberikan tekanan untuk menciptakan tempat kerja yang terorganisir dengan baik, hal ini dapat mencerminkan perlakuan seseorang terhadap pekerjaannya serta sikapnya terhadap pekerjaan [30].

Berbagai instrumen dapat digunakan untuk mencapai tujuan perusahaan, dan instrument yang paling penting adalah sumber daya manusia (SDM) yang merupakan faktor pergerak roda perusahaan, sehingga perusahaan berkewajiban untuk melakukan pengelolaan terhadap SDM- nya dengan sebaik mungkin [31]. Setiap perusahaan pasti berharap para karyawannya mampu melaksanakan pekerjaannya dengan maksimal, hal ini bisa terwujud apabila para karyawan bisa memberikan tingkat produktivitas yang tinggi dalam bekerja [32]. Pelaksanaan pelatihan merupakan salah satu upaya yang dapat dilakukan oleh perusahaan untuk dapat meningkatkan produktivitas kerja karyawannya secara terus menerus kerena melalui pelatihan pengetahuan, keterampilan serta kemampuan karyawan akan meningkat sehingga dapat melaksanakan tugas dan pekerjaan yang dibebankan kepadanya secara efektif dan efisien [33]. Manfaat pelatihan bagi karyawan dapat berupa tambahan pengetahuan, keterampilan kerja, peningkatan prestasi kerja, peningkatan pendapatan dan sebagainya. Sedangkan manfaat bagi perusahaan dapat berupa terjaganya stabilitas perusahaan dan karyawannya [34]. Pelatihan yang efektif akan berdampak pada produktivitas kerja karyawan tidak hanya berkaitan dengan biaya/cost tetapi berarti juga memberikan keuntungan pada perusahaan yaitu peningkatan investasi yang berupa asset manusia [35].

Untuk memenuhi kebutuhan peningkatan produktivitas nasional ada beberapa hal yang perlu dilakukan salah satunya dengan peningkatan produktivitas tenaga kerja dan penguatan daya saing perusahaan termasuk pada instansi pemerintah. Terkait dengan peningkatan produktivitas tenaga kerja dapat dilakukan melalui kegiatan Pelatihan Peningkatan Produktivitas, kegiatan ini merupakan salah satu program yang dilakukan oleh Direktorat Jenderal Pembinaan Pelatihan dan Produktivitas Kementerian Ketenagakerjaan. Tujuan dari kegiatan pelatihan produktivitas adalah untuk peningkatan produktivitas tenaga kerja melalui pembangunan kesadaran pekerja akan pentingnya produktivitas, memberikan pemahaman tentang penerapan teknik-teknik atau metode peningkatan produktivitas di tempat kerja serta metode untuk memelihara tingkat produktivitas yang telah dicapai. Pelatihan peningkatan produktivitas tenaga kerja bertujuan meningkatkan keterampilan dan pengetahuan para pekerja tentang alat teknik dan metode peningkatan produktivitas untuk diimplementasikan di tempat kerjanya, sehingga diharapkan budaya kerja produktif seperti budaya Kaizen 5S dapat diimplementasikan di perusahaan sehingga produktivitas kerja selalu dapat ditingkatkan.

Dalam rangka kesinambungan program Direktorat Jenderal Pembinaan Pelatihan dan Produtivitas juga memiliki program yang dilakukan pasca mengikuti pelatihan peningkatan produktivitas yaitu kegiatan 
Bimbingan Konsultansi peningkatan produktivitas. Perusahaan yang tenaga kerjanya telah mengikuti pelatihan peningkatan produktivitas dapat mengikuti kegiatan bimbingan konsultasi peningkatan produktivitas dalam rangka mempastikan pengetahuan dan keterampilan yang diperoleh diimplementasikan ditempat kerjanya. Kegiatan bimbingan konsultansi dilakukan dengan tujuan agar tercapai peningkatan produktivitas perusahaan melalui penekanan segala bentuk pemborosan ditempat kerja dengan cara penerapan alat teknik dan metode peningkatan produktivitas.

Keberhasilan dari program-program pemerintah tersebut selama ini belum pernah dilakukan evaluasi secara khusus untuk melihat sejauh mana dapat memberikan kontribusi terhadap upaya peningkatan produktivitas tenaga kerja di Indonesia. Oleh karen itu, penelitian ini bertujuan untuk mengkaji secara lebih menyeluruh dampak pelatihan terhadap implemtasi budaya kerja produktiv serta dampak pelatihan dan budaya kerja produktif terhadap peningkatan produktivitas kerja. Pada penelitian-penelitian sebelumnya pada umumnya hanya membahas dampak pelatihan terhadap produktivitas atau dampak implementasi budaya kerja produktif Kaizen 5S terhadap produktivitas kerja. Dalam penelitian ini akan dikaji secara lebih dalam pengaruh implementasi budaya kerja produktif terhadap peningkatan produktivitas baik melalui proses pelatihan maupun tanpa pelatihan yang dilaksanakan oleh pemerintah maupun oleh perusahaan secara mandiri.

\section{METODE PENELITIAN}

\subsection{Teknik Pengambilan Sampel}

Penelitian ini menggunakan data primer yang diperoleh dengan melakukan pengisian kuesioner skala likert. Pemilihan sampel menggunakan teknik purposive sampling. Kriteria dalam pemilihan sampel perusahaan yaitu; perusahaan yang telah memenangkan penghargaan produktivitas, perusahaan yang telah memiliki unit pelatihan produktivitas serta perusahaan yang bersifat konvesional dan perusahaan yang bersifat millenial dengan jumlah total sebanyak 16 perusahaan yang tersebar di seluruh Indonesia. Adapun responden penelitian ini adalah meliputi pihak manajement perusahaan dan karyawan perusahaan dengan jumlah total sebanyak 52 orang responden.

\subsection{Teknik Analisis Data}

Metode analisa data yang digunakan adalah analisis kuantitatif berdasarkan hasil perhitungan statistik dengan menggunakan software Smart PLS, dengan tahapan sebagai berikut:

- Pengujian Outer Model: Terdapat tiga kriteria di dalam penggunaan teknik analisa data dengan SmartPLS untuk menilai outer model yaitu Convergent Validity, Discriminant Validity dan Composite Reliability. Convergent validity dari model pengukuran dengan refleksif indikator dinilai berdasarkan korelasi antara item score/component score yang diestimasi dengan Soflware PLS. Ukuran refleksif individual dikatakan tinggi jika berkorelasi lebih dari 0,70 dengan konstruk yang diukur. Namun untuk penelitian tahap awal dari pengembangan skala pengukuran nilai loading 0,5 sampai 0,6 dianggap cukup memadai. Dalam penelitian ini akan digunakan batas loading factor sebesar 0,60.

- Pengujian terhadap model struktural (Inner Model) : dilakukan dengan melihat nilai R-Square yang merupakan uji goodness-fit model

Pada prinsipnya penelitian ini menggunakan 4 buah variabel yang dipengaruhi oleh variabel lainnya yaitu variabel Budaya 5S (5S) yang dipengaruhi oleh budaya Kaizen (KZ), variabel budaya kaizen yang dipengaruhi oleh Pelatihan Kerja (PK) dan Budaya Kerja Produktif (BK) yang dipengaruhi oleh Pelatihan Kerja. Sementara itu, Produktivitas tidak secara langsung dipengaruhi oleh Budaya Kaizen tetapi melalui budaya $5 \mathrm{~S}$ terlebih dahulu dan kemudian budaya $5 \mathrm{~S}$ mempengaruhi produktivitas secara langsung. Selain itu, produktivitas juga dipengaruhi secara langsung oleh variabel Budaya Kerja Produktif dan Pelatihan Kerja. 


\section{HASIL DAN PEMBAHASAN}

\subsection{Menilai Outer Model atau Measurement Model}

Hasil pengolahan dengan menggunakan Smart PLS dapat dilihat pada Tabel 1 Nilai outer model atau korelasi antara konstruk dengan variabel pada awalnya sudah memenuhi convergen validity karena seluruh sub indikator memiliki nilai loading factor di atas 0,60 . Modifikasi model perlu dilakukan ketika nilai loading factor yang muncul di bawah 0,60. Modifikasi model dilakukan dengan mengeluarkan indikator-indikator yang memiliki nilai loading factor di bawah 0,60 sehingga konstruk untuk semua variabel sudah tidak ada yang dieliminasi dari model.

Tabel 4. Outer Loadings (Measurement Model)

\begin{tabular}{|c|c|c|c|c|c|}
\hline Kode & Budaya 5S & $\begin{array}{c}\text { Budaya Kerja } \\
\text { Produktif }\end{array}$ & $\begin{array}{l}\text { Budaya } \\
\text { Kaizen }\end{array}$ & $\begin{array}{c}\text { Produktivitas } \\
\text { Kerja }\end{array}$ & $\begin{array}{c}\text { Pelatihan } \\
\text { Kerja }\end{array}$ \\
\hline $5 S 1$ & 0.920 & & & & \\
\hline $5 S 2$ & 0.878 & & & & \\
\hline $5 S 3$ & 0.946 & & & & \\
\hline $5 S 4$ & 0.964 & & & & \\
\hline $5 S 5$ & 0.929 & & & & \\
\hline BK 1 & & 0.794 & & & \\
\hline BK 2 & & 0.689 & & & \\
\hline BK 3 & & 0.801 & & & \\
\hline BK 4 & & 0.875 & & & \\
\hline BK 5 & & 0.740 & & & \\
\hline BK 6 & & 0.626 & & & \\
\hline BK 7 & & 0.846 & & & \\
\hline BK 8 & & 0.875 & & & \\
\hline BK 9 & & 0.782 & & & \\
\hline KZ 1 & & & 0.902 & & \\
\hline KZ 2 & & & 0.956 & & \\
\hline KZ 3 & & & 0.817 & & \\
\hline $\mathrm{KZ} 4$ & & & 0.947 & & \\
\hline P 1 & & & & 0.783 & \\
\hline P 2 & & & & 0.866 & \\
\hline P 3 & & & & 0.926 & \\
\hline P 4 & & & & 0.811 & \\
\hline P 5 & & & & 0.877 & \\
\hline P 6 & & & & 0.672 & \\
\hline PK 1 & & & & & 1.000 \\
\hline PK 2 & & & & & 0.900 \\
\hline PK 3 & & & & & 0.804 \\
\hline
\end{tabular}

Sumber: Pengolahan data dengan PLS, 2020

\subsection{Discriminant Validity}

Discriminant validity dilakukan untuk memastikan bahwa setiap konsep dari masing variabel laten berbeda dengan variabel lainnya. Model mempunyai discriminant validity yang baik jika setiap nilai loading dari setiap indikator dari sebuah variabel laten memiliki nilai loading yang paling besar dengan nilai loading lain terhadap variabel laten lainnya. Hasil pengujian discriminant validity diperoleh dapat dilihat pada tabel 2. Dari tabel 4 dapat dilihat bahwa beberapa nilai loading factor untuk setiap indikator dari masing-masing variabel laten mayoritas telah memiliki nilai loading factor yang paling besar dibanding nilai loading jika dihubungkan dengan variabel laten lainnya dimana hanya terdapat dua variabel laten yang memiliki nilai loading factor lebih kecil dibandingkan nilai loading dari variabel laten lainnya. Hal ini berarti bahwa 
mayoritas setiap variabel laten telah memiliki discriminant validity yang memadai/baik dimana mayoritas variabel laten sudah tidak memiliki pengukur yang berkorelasi tinggi dengan konstruk lainnya.

Tabel 2. Nilai Discriminant Validity (Cross Loading)

\begin{tabular}{|c|c|c|c|c|c|}
\hline Kode & Budaya 5S & $\begin{array}{c}\text { Budaya } \\
\text { Kaizen }\end{array}$ & $\begin{array}{c}\text { Budaya Kerja } \\
\text { Produktif }\end{array}$ & $\begin{array}{c}\text { Pelatihan } \\
\text { Kerja }\end{array}$ & $\begin{array}{c}\text { Produktivitas } \\
\text { Kerja }\end{array}$ \\
\hline $5 \mathrm{~S} 1$ & 0.920 & 0.703 & 0.499 & 0.487 & 0.650 \\
\hline $5 \mathrm{~S} 2$ & 0.878 & 0.690 & 0.500 & 0.427 & 0.598 \\
\hline $5 S 3$ & 0.946 & 0.746 & 0.547 & 0.498 & 0.639 \\
\hline $5 S 4$ & 0.964 & 0.771 & 0.557 & 0.550 & 0.639 \\
\hline $5 S 5$ & 0.929 & 0.786 & 0.554 & 0.476 & 0.564 \\
\hline BK 1 & 0.357 & 0.597 & 0.794 & 0.579 & 0.631 \\
\hline BK 2 & 0.343 & 0.323 & 0.689 & 0.313 & 0.500 \\
\hline BK 3 & 0.708 & 0.762 & 0.801 & 0.522 & 0.677 \\
\hline BK 4 & 0.430 & 0.506 & 0.875 & 0.478 & 0.697 \\
\hline BK 5 & 0.507 & 0.711 & 0.747 & 0.810 & 0.669 \\
\hline BK 6 & 0.384 & 0.610 & 0.626 & 0.500 & 0.457 \\
\hline BK 7 & 0.342 & 0.432 & 0.846 & 0.414 & 0.607 \\
\hline BK 8 & 0.474 & 0.563 & 0.875 & 0.471 & 0.774 \\
\hline BK 9 & 0.430 & 0.498 & 0.782 & 0.411 & 0.714 \\
\hline KZ 1 & 0.722 & 0.902 & 0.703 & 0.587 & 0.688 \\
\hline KZ 2 & 0.789 & 0.956 & 0.664 & 0.594 & 0.725 \\
\hline KZ 3 & 0.589 & 0.817 & 0.570 & 0.612 & 0.667 \\
\hline $\mathrm{KZ} 4$ & 0.769 & 0.947 & 0.729 & 0.605 & 0.783 \\
\hline P 1 & 0.487 & 0.622 & 0.664 & 0.615 & 0.783 \\
\hline P 2 & 0.515 & 0.565 & 0.722 & 0.437 & 0.866 \\
\hline P 3 & 0.624 & 0.749 & 0.787 & 0.649 & 0.926 \\
\hline P 4 & 0.418 & 0.482 & 0.713 & 0.441 & 0.811 \\
\hline P 5 & 0.669 & 0.733 & 0.636 & 0.562 & 0.877 \\
\hline P 6 & 0.557 & 0.750 & 0.533 & 0.620 & 0.672 \\
\hline PK 1 & 0.530 & 0.654 & 0.653 & 1.000 & 0.671 \\
\hline PK 2 & 0.500 & 0.591 & 0.598 & 0.900 & 0.592 \\
\hline PK 3 & 0.457 & 0.468 & 0.574 & 0.804 & 0.548 \\
\hline
\end{tabular}

Sumber: Pengolahan data dengan PLS, 2020

\subsection{Mengevaluasi Reliability dan Average Variance Extracted (AVE)}

Kriteria validity dan reliabilitas juga dapat dilihat dari nilai reliabilitas suatu konstruk dan nilai Average Variance Extracted (AVE) dari masing-masing konstruk. Konstruk dikatakan memiliki reliabilitas yang tinggi jika nilainya 0,70 dan AVE berada diatas 0,50. Pada tabel 3 disajikan nilai Composite Reliability dan AVE untuk seluruh variabel. Berdasarkan tabel 3 dapat disimpulkan bahwa semua konstruk memenuhi kriteria reliabel. Hal ini ditunjukkan dengan nilai composite reliability di atas 0,70 dan AVE diatas 0,50 sebagaimana kriteria yang direkomendasikan. Nilai composite reliability bahkan $>0,90$ mengindikasikan bahwa nilai varian error yang kecil (minor).

Tabel 3. Composite Reliability dan Average Variance Extracted

\begin{tabular}{lcc}
\hline \multicolumn{1}{c}{ Variable } & Composite Reliability & $\begin{array}{c}\text { Average Variance Extracted } \\
\text { (AVE) }\end{array}$ \\
\hline Budaya 5S & 1.000 & 1.000 \\
\hline Budaya Kaizen & 1.000 & 1.000 \\
\hline Budaya Kerja Produktif & 0.935 & 0.617 \\
\hline Pelatihan Kerja & 1.000 & 1.000 \\
\hline Produktivitas Kerja & 0.928 & 0.683 \\
\hline
\end{tabular}

Sumber: Pengolahan data dengan PLS, 2020 


\subsection{Pengujian Model Struktural (Inner Model)}

Pengujian inner model atau model struktural dilakukan untuk melihat hubungan antara konstruk, nilai signifikansi dan $R$-square dari model penelitian. Model struktural dievaluasi dengan menggunakan $R$-square untuk konstruk dependen uji t serta signifikansi dari koefisien parameter jalur struktural seperti terlihat pada gambar 2. Dalam menilai model dengan PLS dimulai dengan melihat $R$-square untuk setiap variabel laten dependen. Tabel 4 merupakan hasil estimasi $R$-square dengan menggunakan SmartPLS.

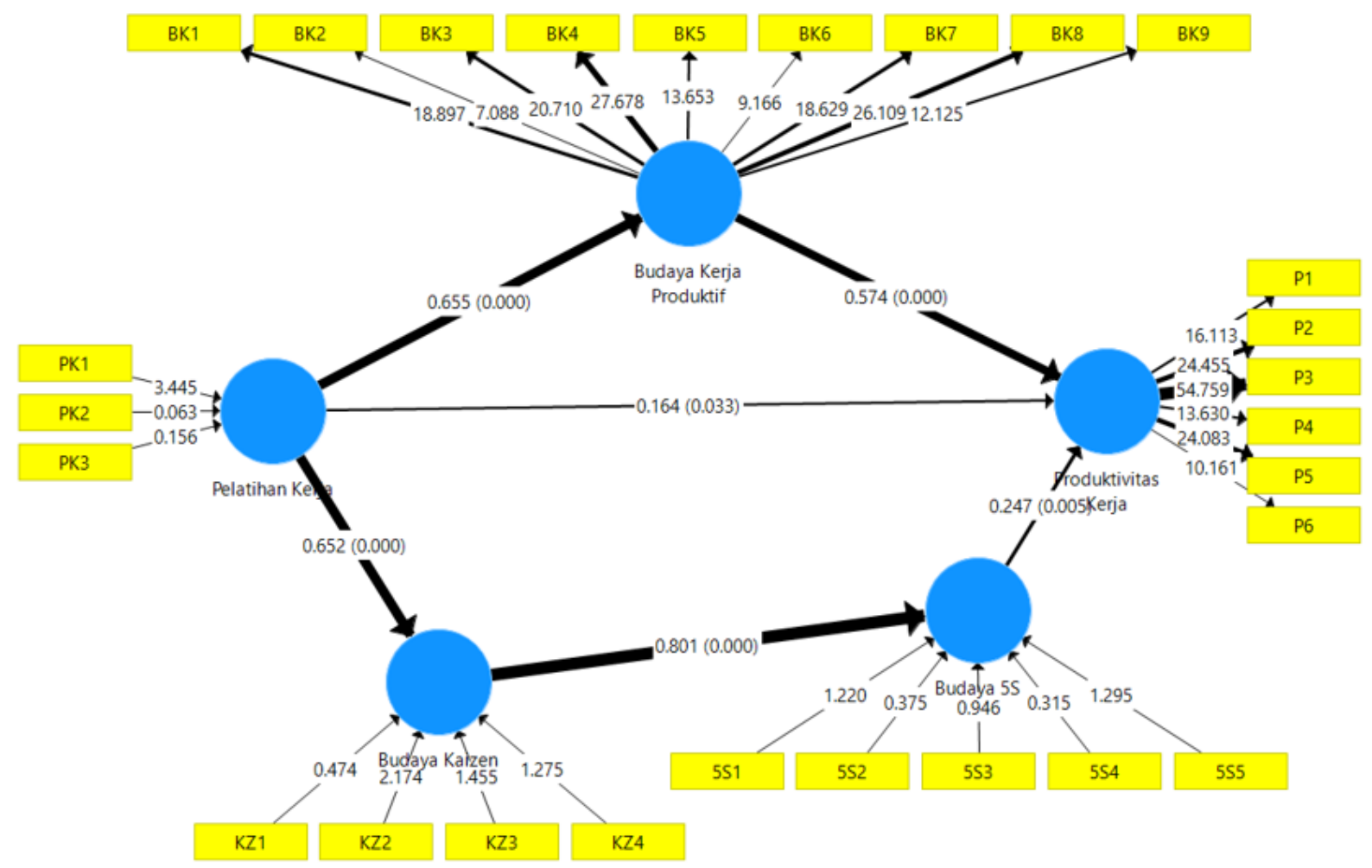

Gambar 2. Model Struktural Analisis Jalur

Sumber: Pengolahan data dengan PLS, 2020

Tabel 4. Nilai R-Square

\begin{tabular}{lc}
\hline \multicolumn{1}{c}{ Variable } & $\boldsymbol{R}$-square \\
\hline Budaya 5S & 0.641 \\
\hline Budaya Kaizen & 0.425 \\
\hline Budaya Kerja Produktif & 0.429 \\
\hline Pelatihan Kerja & 0.745 \\
\hline
\end{tabular}

Sumber: Pengolahan data dengan PLS, 2020

Tabel 4 menunjukkan nilai $R$-square untuk variabel Budaya 5 S diperoleh sebesar 0,641, untuk variabel Budaya Kaizen diperoleh sebesar 0,425, untuk variabel Budaya Kerja Produktif diperoleh sebesar 0,429, dan untuk variabel Pelatihan Kerja diperoleh sebesar 0,745. Hasil ini menunjukkan bahwa 64,1\% variabel Budaya 5S (5S) dapat dipengaruhi oleh budaya Kaizen (KZ), 42,5\% budaya Kaizen (KZ) dipengaruhi oleh Pelatihan Kerja (PK) dan 42,9\% Budaya Kerja Produktif (BK) yang dipengaruhi oleh Pelatihan Kerja.

\subsection{Pengujian Hipotesis}

Signifikansi parameter yang diestimasi memberikan informasi yang sangat berguna mengenai hubungan antara variabel-variabel penelitian. Dasar yang digunakan dalam menguji hipotesis adalah nilai yang terdapat pada output result for inner weight. Tabel 5 memberikan output estimasi untuk pengujian model struktural. 
Tabel 5. Result For Inner Weights

\begin{tabular}{lcccc}
\hline \multicolumn{1}{c}{ Pengaruh Variabel } & $\begin{array}{c}\text { Original } \\
\text { Sample } \\
\text { Estimate (O) }\end{array}$ & $\begin{array}{c}\text { Mean of Sub } \\
\text { samples (M) }\end{array}$ & $\begin{array}{c}\text { Standard } \\
\text { Deviation } \\
\text { (STEDEV) }\end{array}$ & $\begin{array}{c}\text { T-Statistics } \\
(\mid \mathbf{O} / \text { STERR|) }\end{array}$ \\
\hline Budaya $5 \mathrm{~S} \rightarrow$ Produktivitas Kerja & 0.247 & 0.267 & 0.089 & $2.779^{*}$ \\
\hline Budaya Kaizen $\rightarrow$ Budaya $5 \mathrm{~S}$ & 0.801 & 0.814 & 0.046 & $17.341^{*}$ \\
\hline Budaya Kerja Produktif $\rightarrow$ Produktivitas Kerja & 0.574 & 0.566 & 0.084 & $6.821^{*}$ \\
\hline Pelatihan Kerja $\rightarrow$ Budaya Kaizen & 0.652 & 0.679 & 0.068 & $9.546^{*}$ \\
\hline Pelatihan Kerja $\rightarrow$ Budaya Kerja Produktif & 0.655 & 0.672 & 0.062 & $10.524^{*}$ \\
\hline Pelatihan Kerja $\rightarrow$ Produktivitas Kerja & 0.164 & 0.158 & 0.086 & 1.907 \\
\hline Sura
\end{tabular}

Sumber: Pengolahan data dengan PLS, 2020

Dalam PLS pengujian secara statistik setiap hubungan yang dihipotesiskan dilakukan dengan menggunakan simulasi. Dalam hal ini dilakukan metode bootstrap terhadap sampel. Pengujian dengan bootstrap juga dimaksudkan untuk meminimalkan masalah ketidaknormalan data penelitian. Hasil pengujian seperti terlihat pada tabel 5 di atas dengan bootstrapping dari analisis PLS adalah sebagai berikut:

- Pengujian Hipotesis 1 (Budaya 5S berhubungan langsung dan positif terhadap Produktivitas Kerja): Hasil pengujian hipotesis pertama menunjukkan bahwa hubungan variabel Budaya 5S dengan Produktivitas Kerja menunjukkan nilai koefisien jalur sebesar 0,247 dengan nilai t sebesar 2,779. Nilai tersebut lebih besar dari t tabel $(1,960)$. Hasil ini berarti bahwa Budaya $5 \mathrm{~S}$ memiliki hubungan yang positif dan signifikan terhadap Produktivitas Kerja yang berarti sesuai dengan hipotesis pertama dimana Budaya 5S mendorong Produktivitas Kerja. Hal ini berarti Hipotesis 1 diterima.

- Pengujian Hipotesis 2 (Budaya Kaizen berhubungan langsung dan positif terhadap Budaya 5S): Hasil pengujian hipotesis kedua menunjukkan bahwa hubungan variabel Budaya Kaizen dengan Budaya 5S menunjukkan nilai koefisien jalur sebesar 0,801 dengan nilai $t$ sebesar 17,341. Nilai tersebut lebih besar dari $t$ tabel $(1,960)$. Hasil ini berarti bahwa Budaya Kaizen memiliki hubungan yang positif dan signifikan terhadap Budaya 5S yang berarti sesuai dengan hipotesis kedua dimana Budaya Kaizen mendorong Budaya 5S. Hal ini berarti Hipotesis 2 diterima.

- Pengujian Hipotesis 3 (Budaya Kerja Produktif berhubungan langsung dan positif terhadap Produktivitas Kerja): Hasil pengujian hipotesis ketiga menunjukkan bahwa hubungan variabel Budaya Kerja Produktif dengan Produktivitas Kerja menunjukkan nilai koefisien jalur sebesar 0,574 dengan nilai t sebesar 6,821. Nilai tersebut lebih besar dari t tabel $(1,960)$. Hasil ini berarti bahwa Budaya Kerja Produktif memiliki hubungan yang positif dan signifikan terhadap Produktivitas Kerja yang berarti sesuai dengan hipotesis ketiga dimana Budaya Kerja Produktif mendorong Produktivitas Kerja. Hal ini berarti Hipotesis 3 diterima.

- Pengujian Hipotesis 4 (Pelatihan Kerja berhubungan langsung dan positif terhadap Budaya Kaizen): Hasil pengujian hipotesis keempat menunjukkan bahwa hubungan variabel Pelatihan Kerja dengan Budaya Kaizen menunjukkan nilai koefisien jalur sebesar 0,652 dengan nilai t sebesar 9,546. Nilai tersebut lebih besar dari t tabel $(1,960)$. Hasil ini berarti bahwa Pelatihan Kerja memiliki hubungan yang positif dan signifikan terhadap Budaya Kaizen yang berarti sesuai dengan hipotesis keempat dimana Pelatihan Kerja mendorong Budaya Kaizen secara langsung. Hal ini berarti Hipotesis 4 diterima.

- Pengujian Hipotesis 5 (Pelatihan Kerja berhubungan langsung dan positif terhadap Budaya Kerja Produktif): Hasil pengujian hipotesis kelima menunjukkan bahwa hubungan variabel Pelatihan Kerja dengan Budaya Kerja Produktif menunjukkan nilai koefisien jalur sebesar 0,655 dengan nilai t sebesar 10,524. Nilai tersebut lebih besar dari $t$ tabel $(1,960)$. Hasil ini berarti bahwa Pelatihan Kerja memiliki hubungan yang positif dan signifikan terhadap Budaya Kerja Produktif yang berarti sesuai dengan hipotesis kelima dimana Pelatihan Kerja mendorong Budaya Kerja Produktif secara langsung. Hal ini berarti Hipotesis 5 diterima.

\section{Pengujian Hipotesis 6 (Pelatihan Kerja berhubungan langsung dan positif terhadap Produktivitas}

Kerja): Hasil pengujian hipotesis kelima menunjukkan bahwa hubungan variabel Pelatihan Kerja dengan Produktivitas Kerja menunjukkan nilai koefisien jalur sebesar 0,164 dengan nilai t sebesar 1,907. Nilai tersebut lebih kecil dari $t$ tabel $(1,960)$. Hasil ini berarti bahwa Pelatihan Kerja memiliki hubungan yang 
positif tetapi tidak signifikan terhadap Produktivitas Kerja yang berarti tidak sesuai dengan hipotesis keenam dimana Pelatihan Kerja tidak mendorong Produktivitas Kerja secara langsung. Hal ini berarti Hipotesis 6 ditolak.

- Pengujian Hipotesis 7 (Budaya Kaizen berhubungan tidak langsung dan positif terhadap Produktivitas Kerja): Tabel 6 memberikan output estimasi Total Indirect Effects untuk pengujian model struktural. Pengujian hipotesis ketujuh untuk pengujian pengaruh tidak langsung variabel Budaya Kaizen terhadap Produktivitas Kerja melalui Budaya 5S terlebih dahulu. Hubungan tidak langsung tersebut menunjukkan nilai koefisien jalur sebesar 0,197 dengan nilai $t$ sebesar 2,635. Nilai tersebut lebih besar dari t tabel $(1,960)$. Hasil ini berarti bahwa Budaya Kaizen memiliki hubungan yang positif dan signifikan terhadap Produktivitas Kerja secara tidak langsung dimana melalui Budaya 5S terlebih dahulu. Hal itu telah sesuai dengan hipotesis ketujuh dimana Budaya Kaizen mendorong Produktivitas secara tidak langsung. Hal ini berarti Hipotesis 7 diterima.

- Pengujian Hipotesis 8 (Pelatihan Kerja berhubungan tidak langsung dan positif terhadap Budaya 5S): Tabel 6 menunjukkan bahwa pengujian hipotesis kedelapan untuk pengujian pengaruh tidak langsung variabel Pelatihan Kerja terhadap Budaya 5S melalui Budaya Kaizen terlebih dahulu. Hubungan tidak langsung tersebut menunjukkan nilai koefisien jalur sebesar 0,522 dengan nilai t sebesar 6,756. Nilai tersebut lebih besar dari t tabel $(1,960)$. Hasil ini berarti bahwa Pelatihan Kerja memiliki hubungan tidak langsung yang positif dan signifikan melalui Budaya Kerja Produktiv. Hal itu telah sesuai dengan hipotesis kesembilan dimana Pelatihan Kerja mendorong Budaya 5S secara tidak langsung melalui Budaya Kaizen. Hal ini berarti Hipotesis 8 diterima.

- Pengujian Hipotesis 9 (Pelatihan Kerja berhubungan tidak langsung dan positif terhadap Produktivitas Kerja): Tabel 4.6 menunjukkan bahwa pengujian hipotesis kesepulih untuk pengujian pengaruh tidak langsung variabel Pelatihan Kerja terhadap Produktivitas Kerja melalui Budaya Kerja Produktif. Hubungan tidak langsung tersebut menunjukkan nilai koefisien jalur sebesar 0,504 dengan nilai $\mathrm{t}$ sebesar 7,032. Nilai tersebut lebih besar dari t tabel $(1,960)$. Hasil ini berarti bahwa Pelatihan Kerja memiliki hubungan tidak langsung yang positif dan signifikan terhadap Produktivitas Keja. Hal itu telah sesuai dengan hipotesis kesepuluh dimana Pelatihan Kerja mendorong Produktivitas Kerja secara tidak langsung melalui Budaya Kerja Produktif. Hal ini berarti Hipotesis 9 diterima.

Tabel 6. Result for Total Indirect Effects

\begin{tabular}{lcccc}
\hline \multicolumn{1}{c}{ Pengaruh Variabel } & $\begin{array}{c}\text { Original } \\
\text { Sample } \\
\text { Estimate }(\mathbf{O})\end{array}$ & $\begin{array}{c}\text { Mean of Sub } \\
\text { samples (M) }\end{array}$ & $\begin{array}{c}\text { Standard } \\
\text { Deviation } \\
\text { (STEDEV) }\end{array}$ & $\begin{array}{c}\text { T-Statistics } \\
(\mid \mathbf{O} / \text { STERR } \mid \text { ) }\end{array}$ \\
\hline Budaya Kaizen $\rightarrow$ Produktivitas Kerja & 0.197 & 0.217 & 0.075 & $2.635^{*}$ \\
\hline Pelatihan Kerja $\rightarrow$ Budaya 5S & 0.522 & 0.554 & 0.077 & $6.756^{*}$ \\
\hline Pelatihan Kerja $\rightarrow$ Produktivitas Kerja & 0.504 & 0.527 & 0.072 & $7.032^{*}$ \\
\hline
\end{tabular}

Sumber: Pengolahan data dengan PLS, 2020

\section{KESIMPULAN}

Berdasarkan hasil analisis kuantitatif maka dari penelitian ini dapat ditarik beberapa kesimpulan sebagai berikut:

1. Penerapan budaya Kaizen $5 \mathrm{~S}$ di Indonesia untuk perusahaan-perusahaan yang mampu mengimplementasikan secara keseluruhan, memiliki dampak yang signifikan untuk meningkatkan produktivias kerja perusahaan.

2. Untuk dapat mengadopsi budaya Kaizen $5 \mathrm{~S}$ oleh perusahaan-perusahaan di Indonesia, membutuhkan komitment yang kuat dari pihak manajement perusahaan dan karyawan perusahaan untuk bersamasama melakukan proses perubahan sikap dalam rangka meningkatkan kedisiplinan dan kerjasama tim. Upaya yang dapat dilakukan oleh pihak manajement diantaranya dengan menyelenggarakan pelatihan produktivitas secara kontinu. 
3. Program-program pelatihan peningkatan produktivitas dan bimbingan konsultasi yang dilaksanakan oleh pemerintah perlu memperhatikan budaya kerja yang dominan diterapkan oleh perusahaan untuk mencapai produktivitas kerja yang tinggi.

\section{DAFTAR PUSTAKA}

[1] Gardiner, Ben, M. Ron, and T. Peter, "Competitiveness, Productivity and Economic Growth across the European Regions," 2004.

[2] L. Adam, “Membangun Daya Saing Tenaga Kerja Indonesia Melalui Peningkatan Produktivitas,” J. Kependud. Indones., vol. 11, no. 2, pp. 71-84, 2016.

[3] M. Uzik and R. Vokorokosova, "Labor Productivity as a Factor of Competitiveness, A Comparative Study Narodohospodarsky," 2007.

[4] A. . Emsina, "Labor Productivity, Economic Growth, and Global Competitive in Post Crisis Period," Soc. Behav. Sci., vol. 156, no. 2, pp. 317-321, 2014.

[5] Porter, Michael, and C. Ketels, "UK Competitiveness: Moving to the Next Stage," London, 2003.

[6] G. Gugustomo, "Inovasi dan Daya Saing SDM Indonesia di Hardiknas 2019," akurat.co, 2019. https://akurat.co/news/id610211-read-inovasi-dan-daya-saing-sdm-indonesia-di-hardiknas-2019 (accessed Nov. 28, 2020).

[7] A. Rumahlaiselan and R. S. Wenas, "Pengaruh Pelatihan Dan Kompensasi Terhadap Produktivitas Kerja Karyawan Pada PT Sumber Alfaria Trijaya, Tbk Cabang Manado," J. EMBA, vol. 6, no. 4, pp. 3783 - 3792, 2018.

[8] S. Wahyuningsih, "Pengaruh Pelatihan Dalam Meningkatkan Produktivitas Kerja Karyawan,” J. War., vol. 60, 2019.

[9] Rahmawati and Soehardi, "engaruh Budaya Kaizen (5S), Teknologi dan Inovasi Terhadap Produktivitas UMKM di PT Ramadhan Kue, Cianjur,” J. Ilm. Manaj. Ubhara, vol. 4, no. 3, pp. 124-157, 2017.

[10] M. Dewi and D. Teguh, "Implementasi Manajemen 5S pada CV. Rapi Vulkanisir Aceh Besar," Malikussaleh Ind. Eng. J., vol. 2 , no. 2, pp. 10-15, 2013.

[11] A. E. Firman, "Pengendalian Kualitas Menggunakan Pendekatan Kaizen,” J. Din. Tek, vol. 7, no. 2, pp. 1 - 10, 2013.

[12] T. Dian, "Studi Literatur Penerapan Continuous Improvement System (Kaizen) Di Jepang, Cina, Dan Inggris," J. Eksek., vol. 9, no. 2, pp. 262-280, 2012

[13] A. Arga and U. H. Naniek, "Perbaikan Kualitas Menggunakan Prinsip Kaizen Dan 5 Why Analysis: Studi Kasus Pada Painting Shop Karawang Plant 1, PT Toyota Motor Manufacturing Indonesia,” J. Tek. Ind., vol. 13, no. 3, pp. 169 - 176, 2018.

[14] G. Shang and L. Sui Pheng, "Understanding the application of Kaizen methods in construction firms in ChinaNo Title," $J$. Technol. Manag. China, vol. 8, no. 1, pp. 18-33, 2013.

[15] M. F. Suárez-Barraza and J. Ramis-Pujol, "Implementation of Lean-Kaizen in the human resource service process: a case study in a Mexican public service organisation," J. Manuf. Technol. Manag., vol. 21, no. 3, pp. 388-410, 2010.

[16] M. S. Vento, J. L. . Alcaraz, A. M. . Macias, and V. M. Loya, "The Impact Of Managerial Commitment And Kaizen Benefits On Companies," J. Manuf. Technol. Manag., vol. 27, no. 5, pp. 692-712, 2016.

[17] H. Widya and Sukardi, "Pengaruh Budaya Kaizen Dan Budaya Horenso Terhadap Produktivitas Kerja Karyawan Di PT. Yamaha Music Indonesia Manufacturing Asia Cikarang Barat,” J. Ilm. Manaj., vol. 10, no. 2, pp. 210-223, 2020.

[18] N. R. P. Novaldi and M. Mochammad Al, "Analisis Penerapan Budaya Kaizen Pada Perusahaan Joint Venture Asal Jepang D Indonesia (Studi pada PT. X),” J. Adm. Bisnis, vol. 57, no. 1, pp. $188-197,2018$

[19] A. A. Smadi, "Kaizen strategy and the drive for competitiveness: challenges and opportunities," An Int. Busniess J., vol. 19, no. 3, pp. 203-211, 2009

[20] A. S. Nurlaeli and Novita, "Kaizen Costing Sebagai Perbaikan Berkelanjutan Untuk Meningkatkan Keunggulan Bersaing Pada E-Commerce," J. Kaji. Akunt., vol. 3, no. 1, pp. 18-43, 2019.

[21] Yohendry, H. Osrita, and S. Yunan, "Implementasi Kaizen Terhadap Efisiensi Biaya Produksi PT. Dasa Anugerah Sejati Asian Agri Jambi,” J-MAS, vol. 2, no. 2, pp. 196-205, 2017.

[22] P. Erix and F. Rosaly, "Analisis Pengaruh Budaya Kaizen Terhadap Kinerja Karyawan Dengan Reward Sebagai Variabel Moderasi Dalam Rangka Penguatan Daya Saing Bisnis," J. Ekon. Manaj. Sumber Daya, vol. 20, no. 1, pp. 52 - 62, 2018.

[23] W. G. Macpherson, J. C. Lockhart, H. Kavan, and A. L. Iaquinto, "Kaizen: a Japanese philosophy and system for business excellence," J. Bus. Strategy, vol. 36, no. 5, pp. 3-9, 2015.

[24] A. Fatkhurrohman and Subawa, "Penerapan Kaizen Dalam Meningkatkan Efisiensi Dan Kualitas Produk Pada Bagian Banbury PT Bridgestone Tire Indonesia," J. Adm. Kant., vol. 4, no. 1, pp. 14-31, 2016.

[25] T. Karkoszka and Honorowicz, "Kaizen Philosophy a Manner of Continuous Improvement of Processes and Products," $J$ Achiev. Mater. Manuf. Eng., vol. 35, no. 2, 2009.

[26] P. R. Dian and W. Dika, "Penerapan 5S (Seiri, Seiton, Seiso, Seiketsu, Shitsuke) Sebagai Upaya Pengurangan Waste Pada PT X," J. Sist. Tek. Ind., vol. 21, no. 1, pp. 51 - 63, 2019.

[27] S. Agus, "Pengaruh Sikap Kerja 5S (Seiri, Seiton, Seiso, Seiketsu, Shitsuke) Terhadap Produktivitas," Ris. Manaj. Akunt. Vol., vol. 5 , no. 9 , pp. $23-31,2014$

[28] E. E. Agustina, "Terapan 5S dalam Peningkatan Produktivitas berdasarkan Permenaker Nomor 5 Tahun 2018," HIGEIA J. Public Heal. Res. Dev., vol. 4, no. 2, pp. 201-211, 2020.

[29] Indiani, "Perancangan prosedur pemeliharaan ayam broiler sesuai konsep 5S untuk meningkatkan produktivitas," J. Teknol. Technoscientia, vol. 3, pp. 97-104, 2010.

[30] S. Willy, "Rancangan Sikap Kerja 5S di UD Bintang Harapan Surabaya," J. Ilm. Mhs. Univ. Surabaya, vol. 3, no. 2, pp. 1-13, 2014.

[31] D. Rosalia, J. Dwiharto, and Y. Oktafiah, "Pengaruh Pelatihan Dan Pengalaman Kerja Terhadap Produktivitas Karyawanjaya Sakti Sentosa," J. EMA - Ekon. Manaj. Akunt., vol. 2, no. 2, pp. 64-71, 2018.

[32] A. F. Rodli, "Pengaruh Pelatihan Kerja, Pengalaman Kerja Dan Pendidikan Terhadap Produktivitas Kerja," J. Ecopreneur, vol 2 , no. 2 , pp. 31-35, 2019 
[33] P. Andi, S. Herman, and M. M. Abd, "Pengaruh Pelatihan dan Motivasi Kerja Terhadap Produktivitas Pegawai," J. Organ. Dan Manaj., no. 1, pp. 66-81, 2018.

[34] M. S. Undang and M. A. Firdaus, "Pengaruh Pelatihan Terhadap Produktivitas Kerja Karyawan Pada Pt. Sapta Sarana Sejahtera," J. Ilm. Inov., 2014.

[35] E. Haryati and J. D. Sibarani, "Pengaruh Pelatihan Terhadap Produktivitas Kerja Karyawan Pada PT PP. London Sumatera Indonesia, Tbk Medan,” J. Bisnis Adm., vol. 4, no. 2, pp. 32-58, 2015. 
